\title{
Current era minimally invasive aortic valve replacement: Techniques and practice
}

\author{
S. Chris Malaisrie, MD, ${ }^{\mathrm{a}}$ Glenn R. Barnhart, MD, ${ }^{\mathrm{b}}$ R. Saeid Farivar, MD, PhD, ${ }^{\mathrm{c}}$ John Mehall, MD, ${ }^{\mathrm{d}}$ \\ Brian Hummel, MD, ${ }^{\mathrm{e}}$ Evelio Rodriguez, MD, ${ }^{\mathrm{f}}$ Mark Anderson, MD, ${ }^{\mathrm{g}}$ Clifton Lewis, MD, ${ }^{\mathrm{h}}$ \\ Clark Hargrove, MD, ${ }^{\mathrm{i}}$ Gorav Ailawadi, MD,${ }_{\mathrm{j}}$ Scott Goldman, MD, ${ }^{\mathrm{k}}$ Junaid Khan, MD, \\ Michael Moront, MD, ${ }^{\mathrm{m}}$ Eugene Grossi, MD, ${ }^{\mathrm{n}}$ Eric E. Roselli, MD, ${ }^{\circ}$ Arvind Agnihotri, MD, ${ }^{\mathrm{p}}$ \\ Michael J. Mack, MD, ${ }^{\mathrm{q}}$ J. Michael Smith, MD, ${ }^{\mathrm{r}}$ Vinod H. Thourani, MD, ${ }^{\mathrm{s}}$ Francis G. Duhay, MD, \\ Mark T. Kocis, ${ }^{t}$ and William H. Ryan, MD ${ }^{\mathrm{u}}$
}

\begin{abstract}
Background: Since the first aortic valve replacement through a right thoracotomy was reported in 1993, upper hemisternotomy and right anterior thoracotomy have become the predominant approaches for minimally invasive aortic valve replacement. Clinical studies have documented equivalent operative mortality, less bleeding, and reduced intensive care/hospital stay compared with conventional sternotomy despite longer procedure times. However, comparative trials face challenges due to patient preference, surgeon bias, and the lack of a standardized minimally invasive surgical approach.
\end{abstract}

\begin{abstract}
Methods: Twenty cardiothoracic surgeons from 19 institutions across the United States, with a combined experience of nearly 5000 minimally invasive aortic valve replacement operations, formed a working group to develop a basis for a standardized approach to patient evaluation, operative technique, and postoperative care. In addition, a stepwise learning program for surgeons was outlined.
\end{abstract}

Results: Improved cosmesis, less pain and narcotic use, and faster recovery have been reported and generally accepted by patients and by surgeons performing minimally invasive aortic valve replacement. These benefits are more likely to be verified with standardization of the procedure itself, which will greatly facilitate the design and implementation of future clinical studies.

Conclusions: Surgeons interested in learning and performing minimally invasive aortic valve replacement must have expertise in conventional aortic valve replacement at centers with adequate case volumes. A team approach that coordinates efforts of the surgeon, anesthesiologist, perfusionist, and nurses is required to achieve the best clinical outcomes. By first developing fundamental minimally invasive skills using specialized cannulation techniques, neck lines, and long-shafted instruments in the setting of conventional full sternotomy, the safest operative environment is afforded to patients. (J Thorac Cardiovasc Surg 2014;147:6-14)

From Northwestern University, ${ }^{\text {a }}$ Chicago, Ill; Swedish Medical Center, ${ }^{\text {b }}$ Seattle, Wash; University of Pennsylvania, ${ }^{c}$ Philadelphia, Pa; Penrose St Francis Health Systems, ${ }^{\mathrm{d}}$ Colorado Springs, Colo; Gulf Coast Cardiothoracic, ${ }^{\mathrm{e}} \mathrm{Ft}$ Myers, Fla; St Thomas Heart Hospital, ${ }^{\mathrm{f}}$ Nashville, Tenn; Albert Einstein Medical Center, ${ }^{\mathrm{g}}$ Phila-

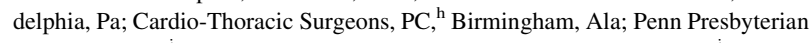
Medical Center, ${ }^{\mathrm{i}}$ Philadelphia, Pa; University of Virginia Health System, ${ }^{\mathrm{j}}$ Charlottesville, Va; Lankenau Hospital, ${ }^{\mathrm{k}}$ Wynnewood, Pa; Alta Bates Summit Medical Center, ${ }^{1}$ Oakland, Calif; The Toledo Hospital, ${ }^{\mathrm{m}}$ Toledo, Ohio; New York University School of Medicine, ${ }^{\mathrm{n}}$ New York, NY; Cleveland Clinic Foundation, ${ }^{\circ}$ Cleveland, Ohio; Massachusetts General Hospital, ${ }^{\mathrm{p}}$ Boston, Mass; Baylor Heart Hospital, ${ }^{\mathrm{q}}$ Dallas, Tex; Hatton Institute, ${ }^{\mathrm{r}}$ Good Samaritan Hospital, Cincinnati, Ohio; Emory University School of Medicine, ${ }^{\mathrm{s}}$ Atlanta, Ga; Edwards Lifesciences, ${ }^{\mathrm{t}}$ Irvine, Calif; and Baylor Heart Hospital, ${ }^{\text {" Dallas, Tex. }}$

Disclosures: Edwards Lifesciences provided reasonable travel, lodging, and honorarium for participation by many of the authors in a medical advisory board meeting where, as one of the agenda topics, initial concepts for the minimally invasive aortic valve replacement manuscript were validated. Authors were not compensated for any time spent writing or reviewing this manuscript and claim full responsibility for the integrity of this work. S. Chris Malaisrie reports lecture fees from Edwards Lifesciences and Medtronic. Glenn R. Barnhart reports consulting fees from Edwards, and lecture fees from Edwards and Atricure. R. Saeid Farivar reports consulting fees from Edwards. John Mehall reports consulting fees from Edwards. Brian Hummel reports consulting fees from Edwards, St. Jude, and Estech. Evelio Rodriguez reports consulting fees from Cardionet, Edwards, and Atricure and lecture fees and grant support from Medtronic. Mark Anderson reports consulting fees from Abiomed and Edwards. Clifton Lewis reports consulting fees from Edwards. Clark Hargrove reports consulting fees from Edwards and Sorin. Gorav Ailawadi reports consulting fees from Edwards, Atricure, Mitralign, and Abbott and lecture fees from St. Jude. Scott Goldman reports consulting fees from Edwards, St. Jude, and LSI. Junaid Khan reports consulting and lecture fees from Edwards. Michael Moront reports consulting fees from Edwards, Medtronic, and Terumo and lecture fees from Medtronic. Eugene Grossi reports consulting fees from Edwards and Medtronic. Eric E. Roselli reports consulting fees from Edwards and Medtronic. Arvind Agnihotri reports consulting fees from Edwards and lecture fees from Intuitive Surgical. Michael J. Mack reports consulting fees from Edwards. J. Michael Smith reports consulting fees from Atricure. Vinod H. Thourani reports consulting fees from Edwards. Francis G. Duhay is a full-time employee of Edwards Lifesciences. Mark T. Kocis is a full-time employee of Edwards Lifesciences. William H. Ryan reports consulting fees from Edwards and Medtronic. Received for publication June 3, 2013; revisions received Aug 21, 2013; accepted for publication Aug 29, 2013; available ahead of print Nov 4, 2013.

Address for reprints: William H. Ryan, MD, Baylor Heart Hospital, 4646 Kelsey Rd, Dallas, TX 75219 (E-mail: whryanmd@yahoo.com).

$0022-5223 / \$ 36.00$

Copyright (c) 2014 by The American Association for Thoracic Surgery http://dx.doi.org/10.1016/j.jtcvs.2013.08.086 

Abbreviations and Acronymns
$\mathrm{CPB}=$ cardiopulmonary bypass
$\mathrm{CT}=$ computed tomography
MIAVR $=$ minimally invasive aortic valve replacment
RAT = right anterior thoracotomy
TEE = transesophageal echocardiography
UHS = upper hemisternotomy

Peripheral vascular disease elevates the risk of stroke or systemic embolization with retrograde arterial perfusion. CT angiography of the chest, abdomen, and pelvis is performed routinely when retrograde perfusion is considered. Severity, location, and nature of atherosclerosis are assessed. ${ }^{17}$ Smooth, calcified plaque is less hazardous than soft or irregular plaque. Size and tortuosity of the iliofemoral vessels are important factors in selecting the appropriate arterial cannula. ${ }^{18}$

In patients with previous cardiac surgery or chest wall irradiation, a chest CT conveys the distance between the posterior sternal table and right ventricle. ${ }^{19}$ The presence of patent coronary bypass grafts crossing the midline is particularly hazardous. For RAT, previous pneumonia, pneumothorax, recurrent lung infections, or right lung resection may be associated with dense pleural adhesions. MIAVR should be approached cautiously in patients with severe chest wall deformities, such as pectus excavatum and kyphoscoliosis, and may be avoided depending on the severity of the abnormality.

Preoperative evaluation for coexistent coronary artery disease is similar to sternotomy patients. Concomitant coronary disease does not preclude MIAVR, and isolated lesions can be managed percutaneously either before or after MIAVR depending on clinical presentation. Importantly, iatrogenic dissection of the iliac artery during cardiac catheterization may be occult, and usually is confined to a tortuous segment as it emerges from the pelvis. If not recognized, acute dissection into the aorta can be induced by retrograde arterial perfusion. For this reason, CT angiography should be performed after cardiac catheterization, if possible (Glenn R. Barnhart, MD, personal communication, November 2012) (Figure 1).

For UHS with direct ascending aortic cannulation, a noncontrast chest CT is used to evaluate the severity and distribution of aortic atherosclerosis, and to formulate cannulation and crossclamp strategies. In bicuspid aortic valve disease, the aortic root and ascending aorta are evaluated to determine if concomitant replacement is indicated. Also, a noncontrast CT confirms to which intercostal space to extend the $J$.

For RAT, chest CT facilitates preoperative planning in 2 ways. First, by conveying the location of the aortic valve, CT identifies those patients best suited for RAT. In particular, if more than one-half of the ascending aorta is positioned to the right of a vertical line drawn from the right sternal border to the ascending aorta in the axial CT view, RAT is appropriate ${ }^{20}$ (Figure 2, $A$ ). Second, by noting which intercostal space is closest to the tip of the right atrial appendage, the preferred intercostal space is identified (Figure 2, B).

\section{INTRAOPERATIVE}

MIAVR requires a coordinated effort by the surgeon, anesthesiologist, perfusionist, and nurses to achieve the 


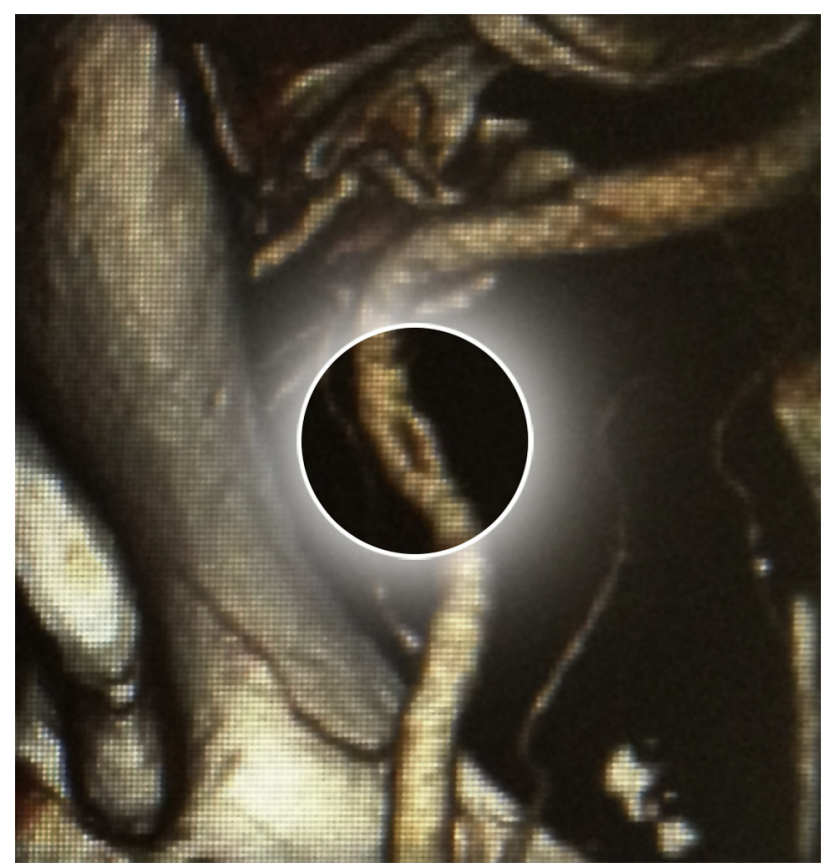

FIGURE 1. Computed tomography reconstruction demonstrates an iatrogenic dissection of the external iliac artery after cardiac catheterization.

best clinical outcomes. Intraoperative transesophageal echocardiography (TEE) is used routinely. ${ }^{21}$ A pulmonary artery catheter is employed based on patient risk and the specific operation. If peripheral cardiopulmonary bypass $(\mathrm{CPB})$ is planned, limb perfusion is monitored using pulse oximetry on the foot during femoral cannulation, or using a radial arterial line during axillary cannulation. The right internal jugular vein is usually cannulated by the anesthesiologist for placement of the retrograde cardioplegia catheter $(11 \mathrm{Fr})$ and pulmonary artery vent $(9 \mathrm{Fr})$, which reduces the number of cannulae arising from the incision.

A single lumen endotracheal tube is standard for both UHS and RAT. To achieve optimal exposure during RAT, the right lung can be mechanically retracted posteriorly without resorting to single-lung ventilation.

Compared with central venous cannulation, peripheral access uses smaller cannula to traverse the inferior vena cava. To improve emptying of the heart during CPB, vacuum-assisted or kinetic venous drainage is commonly used.

The patient is positioned supine and surgically prepped from the neck to mid-thigh. External defibrillator pads are placed similar to reoperative surgery.

\section{UHS APPROACH}

UHS may be the best approach for less experienced MIAVR surgeons. It can be performed without any specialized equipment and can be applied to both primary and reoperative surgery, with either central or peripheral CPB. ${ }^{22}$

Preoperative chest CT identifies the aortic valve relative to the surface anatomy of the bony thorax, thus guiding precise incision placement (Figure 3,A). A vertical skin incision measuring 5 to $8 \mathrm{~cm}$ is made just caudal to the sternal angle of Louis (Figure 3, B). Skin and subcutaneous tissue is undermined exposing the sternal notch superiorly and the intercostal space inferiorly without having to extend the skin incision. The center of the sternum and right interspace is scored using electrocautery. The J-shaped incision is extended into the right fourth interspace or, occasionally, the third intercostal space depending on the preoperative chest CT (Figure 3, C). For those patients who do not have a preoperative chest $\mathrm{CT}$ as well as for surgeons new to MIAVR, the fourth interspace is usually the best option for optimizing exposure.

A sternal saw is used and the right internal thoracic artery is spared. A rigid retractor with narrow blades is inserted (Appendix 1, 1). The pericardium is opened vertically, and pericardial sutures are placed on each side at the level of the aorta, right atrium, and inferior vena cava. The retractor is then removed and the pericardial sutures are affixed 1 to $2 \mathrm{~cm}$ lateral to the skin edge. This enhances
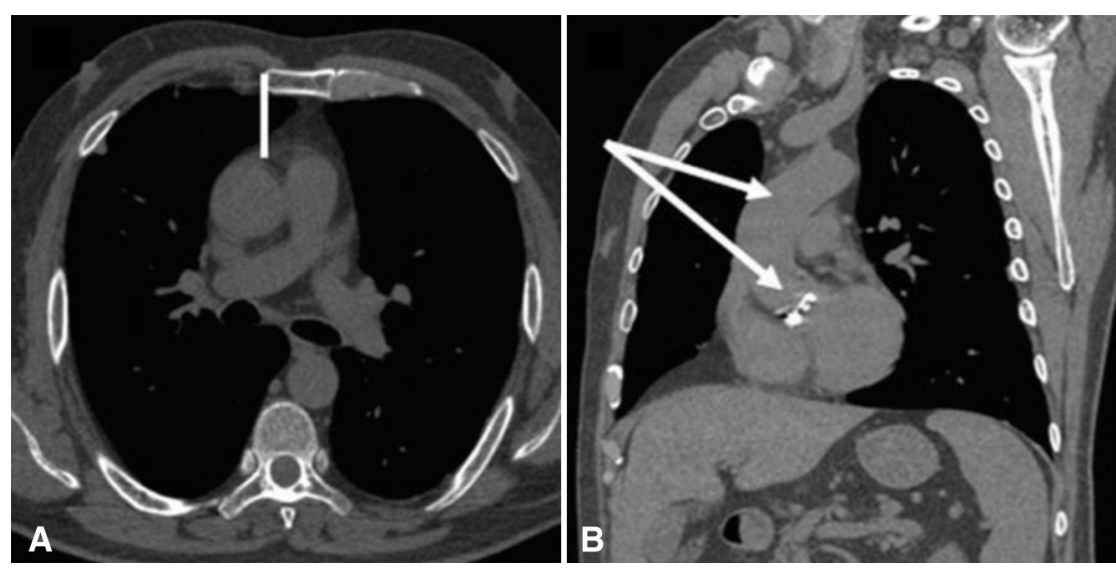

FIGURE 2. Preoperative chest computed tomography. A, Axial plane. B, Sagittal plane. Reprinted from reference 20, with permission from Elsevier. 

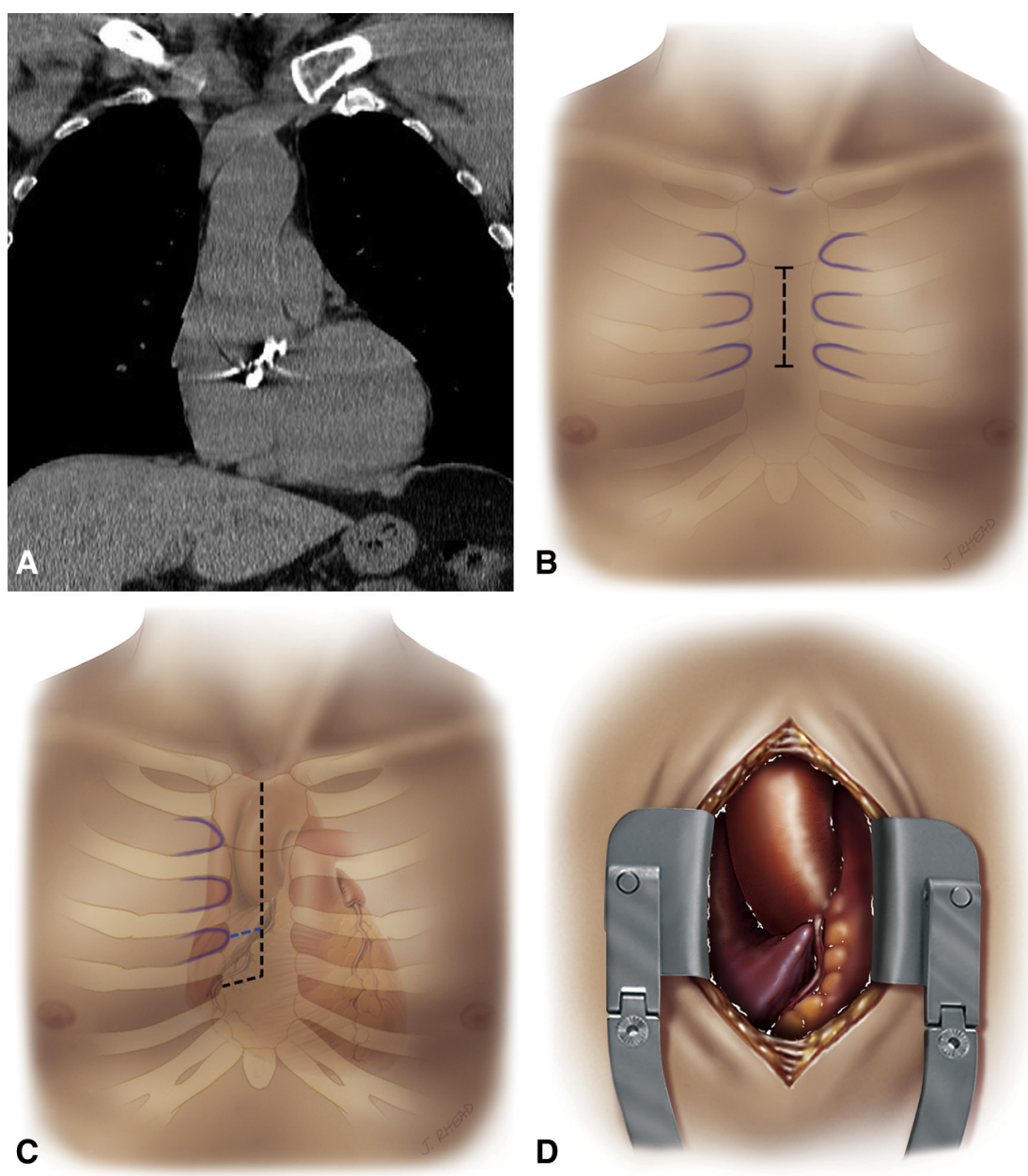

FIGURE 3. Preoperative chest computed tomography identifying (A) the location of the aortic valve relative to the chest wall, (B) skin incision for upper hemisternotomy, (C) J incision into the right fourth (black) or third (blue) intercostal space, and (D), surgical exposure.

exposure by displacing the aorta and heart anteriorly and cranially. Occasionally, hypotension occurs due to impaired venous return, and is managed by reinserting the retractor, infusing intravenous fluid, or both. The operative field is insufflated with carbon dioxide delivered through a catheter via a separate stab incision, which is later used for chest tube insertion. UHS allows exposure of the entire aorta and right atrial appendage (Figure 3,D).

Central cannulation for CPB can be performed through the UHS (Figure 4). After systemic heparinization, intraoperative TEE or epiaortic ultrasound scanning, combined with preoperative chest CT, are used to identify a site on the aorta free of significant atheromatous disease. The ascending aorta is cannulated as distal as possible to provide an unencumbered working space.

Smaller aortic cannulae are preferred (Appendix 1,2). Venous cannulation is performed through the right atrium in standard fashion (Appendix 1, 3). To further reduce cannula traffic, percutaneous femoral venous cannulation may be considered. The right common femoral vein is punctured with an 18-gauge needle and a standard, soft, J-tipped wire is advanced into the superior vena cava under TEE guidance. After serial dilatation of the soft tissue tract and vein, a multiside hole venous cannula (Appendix 1,4) is advanced with its tip positioned $2 \mathrm{~cm}$ into the superior vena cava. At the end of operation, the venous puncture is closed using a 2-0 polypropylene, deep horizontal mattress suture. Venous drainage is facilitated by vacuum or kinetic assistance.

Delivery of cardioplegia can be performed using both antegrade and retrograde routes, similar to conventional aortic valve replacement. For the antegrade approach, the cannula can be removed after delivery of cardioplegia to provide additional visual exposure of the aortic root (keeping the suture in place and replacing the cannula after aortotomy closure). For the retrograde approach, TEE is used to guide placement of the catheter because the coronary sinus cannot be palpated through the UHS incision. The left ventricle can be vented directly through the aortic valve using cardiotomy 


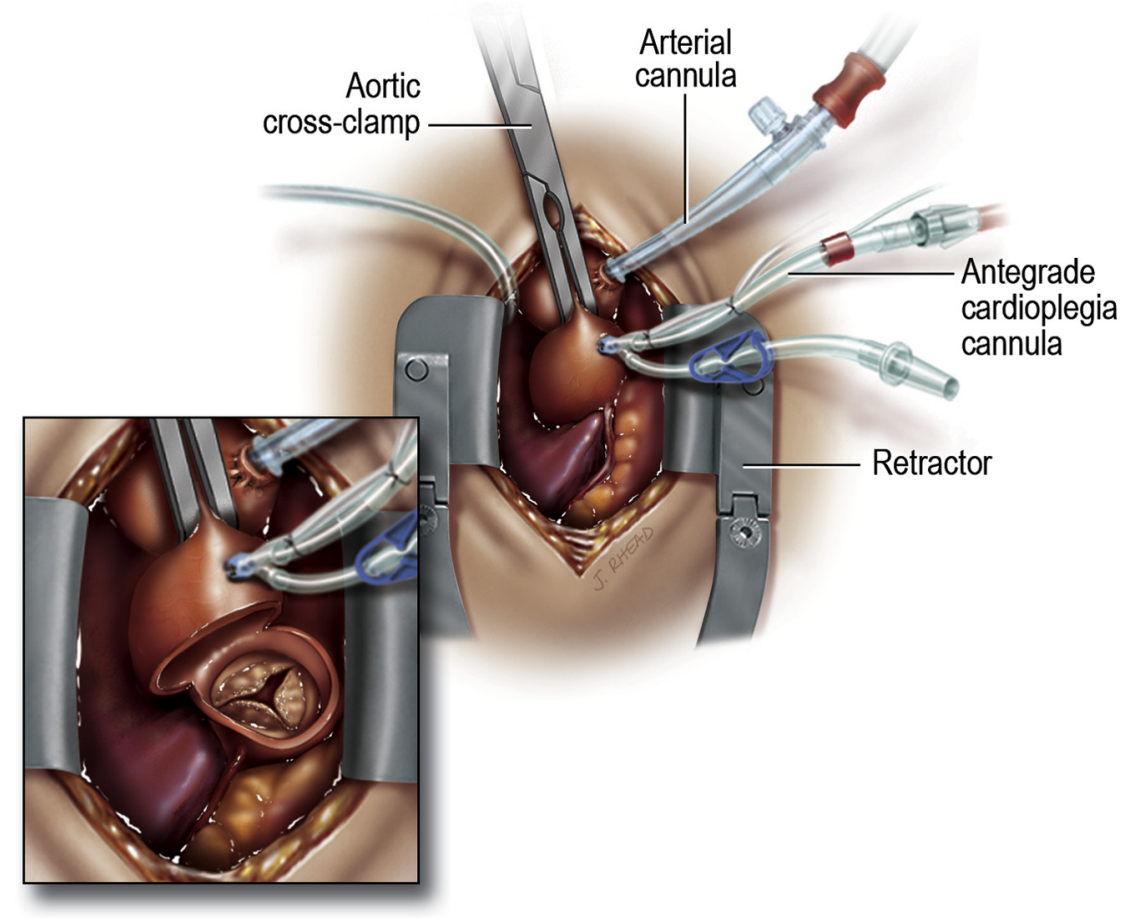

FIGURE 4. Upper hemisternotomy with central cannulation for cardiopulmonary bypass.

suction or indirectly with a percutaneously placed pulmonary artery vent.

After CPB is initiated, the heart is visually inspected to ensure adequate decompression. Poor drainage suggests a malpositioned cannula, which can be remedied by adjusting its position. The aorta is occluded with a standard aortic crossclamp. Other low-profile clamps can be used to maximize working space (Appendix 1,5).

A transverse aortotomy is placed slightly higher to facilitate its closure and visualization at the end of operation. Retraction sutures are placed on the edges of the aortotomy, and at the peak of each commissure to elevate the aortic valve into the center of the operative field. The valve is excised in standard fashion. The annulus is sized and formal annular enlargement can be performed, if necessary. Placement of the aortic valve sutures is facilitated by instruments with long handles. A knotting device is optional, as it can reduce valve implant time. The aortotomy is closed in usual fashion. Temporary epicardial wires, or a single-lead bipolar wire, are affixed to the decompressed right ventricle before the aortic crossclamp is removed, and passed through or near the skin incision via the intercostal space. Because the surface of the heart is not readily accessible, de-airing demands meticulous attention to detail and is monitored using TEE. The heart is partially filled with blood and the lungs are gently ventilated before aortotomy closure, which allows egress of air. Suction is applied to the aortic root vent before the crossclamp is removed. If necessary, electrical defibrillation is accomplished using the external pads. Prosthetic valve function and cardiac performance are assessed by TEE.

Surgical hemostasis is ensured. A single pericardial drain is placed (Appendix 1, 6 ) and the pericardium is closed.

The sternum is reapproximated using steel cerclage wires and augmented as needed with titanium plates (Appendix 1, 7). Stability of the manubrium is critical to minimize postoperative discomfort. Intercostal nerve block using a long-acting local anesthetic such as bupivacaine is injected into the intercostal nerve bundle. Additionally, reservoir devices that permit continuous delivery of topic local anesthetic agents can be used (Appendix 1, 8).

The catheter is usually positioned over the sternal wires and through the skin at the inferior aspect of the incision. The wound is closed in customary fashion.

\section{RAT APPROACH}

RAT avoids sternotomy and is associated with a limited skin incision. However, the operative field is smaller and the aortic valve sits deeper within the wound. Exposure is enhanced by minimizing cannula traffic within the incision, coupled with strategic placement of pericardial sutures.

Before skin incision, peripheral cannulation is performed. Laterality is based on iliofemoral size, calcification, and tortuosity on the preoperative CT angiogram. If both iliofemoral vessels are adequate, the right side is preferred because unlike the left, the right iliac vein is not compressed by the artery as it crosses the pelvic brim. Slight 


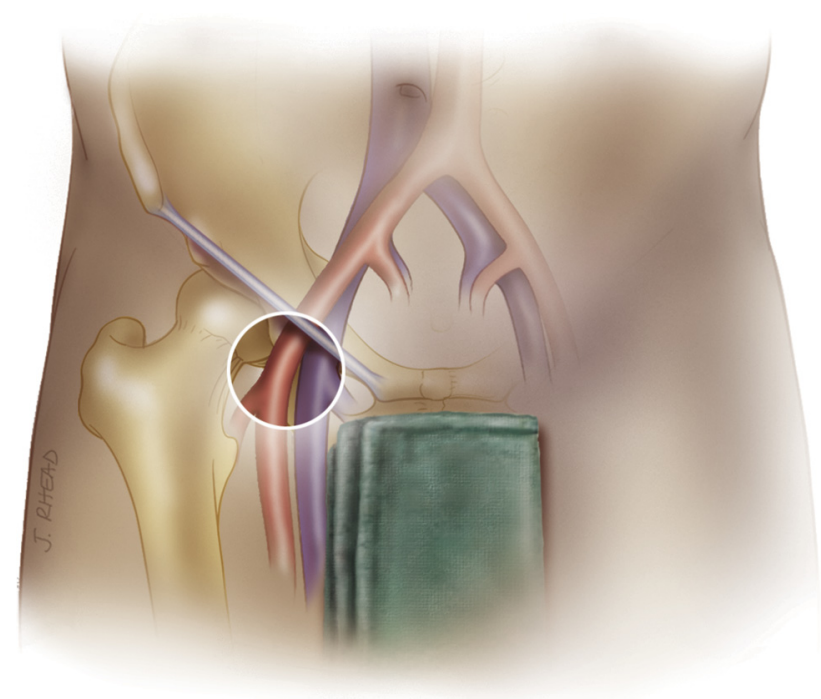

FIGURE 5. Technique of femoral cannulation for cardiopulmonary bypass.

hyperextension of the hips facilitates safe advancement of the cannula across the pelvis. A small oblique incision $(4 \mathrm{~cm})$ is made over the common femoral vessels, which, in most cases, corresponds to an area just above the groin crease. In obese patients, the groin crease often is caudal, so the incision is made slightly higher at the level of the inguinal ligament (Figure 5).

Both common femoral artery and vein are exposed anteriorly, and 4-0 polypropylene purse-string sutures are placed. A soft, J-tipped guidewire is advanced under TEE guidance through the common femoral vein into the superior vena cava using an 18-gauge needle. Avoid advancing the wire into the right atrial appendage, a patent foramen ovale, tricuspid valve, or coronary sinus. A multiside-hole femoral venous cannula is then passed over the wire, positioning its tip $2 \mathrm{~cm}$ within the superior vena cava. If any resistance is encountered while advancing the cannula, the soft wire may be exchanged for a stiff one. Wire exchange is accomplished by first placing a 6-Fr sheath over the wire into the vein. Next, a straight-tip catheter (Appendix 1,9) is advanced over the wire to the level of the superior vena cava (Note: Some wires are 0.038 inch and do not fit in all catheters). The soft wire is then exchanged for a stiff wire at least 260 $\mathrm{cm}$ in length (Appendix 1, 10).

Using Seldinger technique the common femoral artery is cannulated (Appendix 1,11) and its tip is positioned within the external iliac artery to avoid obstructing the internal iliac artery. To allow antegrade perfusion around the cannula to the distal limb, no tourniquets or clamps are placed on the femoral artery. If evidence of limb ischemia is observed, a 14-gauge catheter can be inserted into the femoral artery distally and connected to the arterial cannula.

A percutaneous retrograde cardioplegia catheter (Appendix 1,12) is placed through the right internal jugular vein by the anesthesiologist using TEE (Figure $6, A$ ) or fluoroscopic guidance (Figure 6, B). Similar to placing a Swan Ganz catheter, a percutaneous pulmonary artery vent (Appendix 1,13) is also inserted.

In general, a 4 to $6 \mathrm{~cm}$ skin incision is made over the right third intercostal space near the sternal border (Figure 7, A); however, its location may be modified based on the preoperative chest CT. Upon entering the pleural space, the right internal thoracic vessels are usually ligated and divided. The third or fourth rib can be dislocated from the sternum to enhance exposure with the goal of visualizing the tip of the right atrial appendage. A soft tissue retractor (Appendix 1, 14) is inserted into the wound followed by a rigid retractor with narrow blades (Figure $7, B$ ). Pericardial fat is excised while avoiding the right phrenic nerve. Pericardiotomy is performed 3 to $4 \mathrm{~cm}$ anterior and parallel to the nerve, extending inferiorly toward the diaphragm and superiorly to the pericardial reflection. The pericardium is retracted by passing sutures through the chest wall away from the incision. The operative field is insufflated with carbon dioxide gas similar to UHS.

An antegrade cardioplegia needle is inserted directly into the ascending aorta, and a low-profile aortic crossclamp is
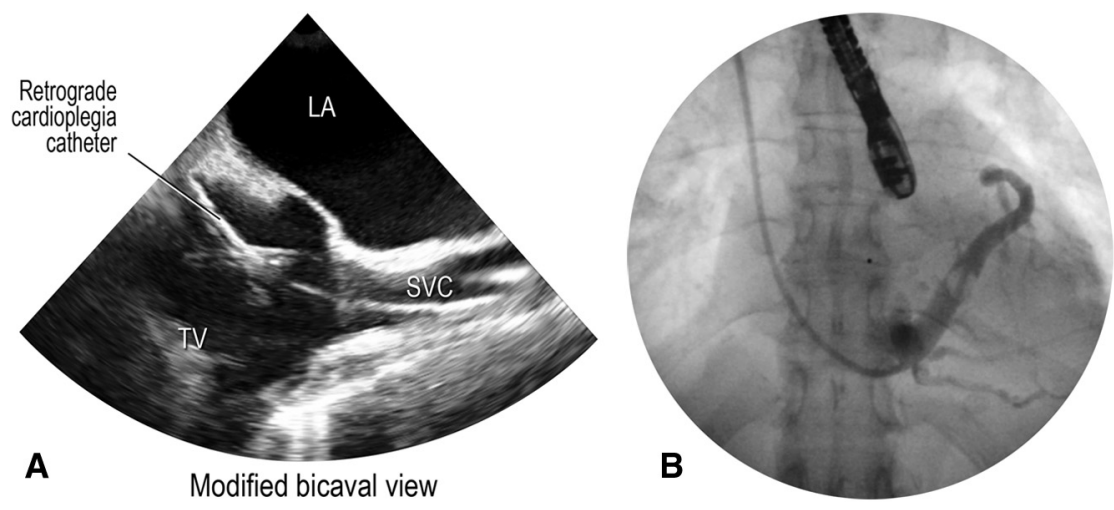

FIGURE 6. Placement of the percutaneous; retrograde cardioplegia catheter using (A) transesophageal echocardiography and (B) fluoroscopic guidance. $L A$, Left atrium; $T V$, tricuspid valve; $S V C$, superior vena cava. 

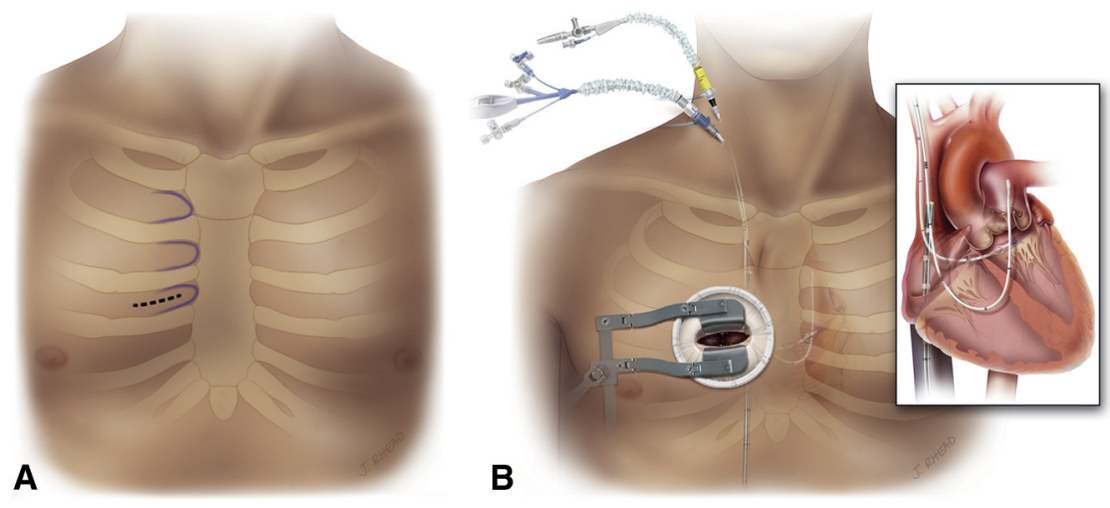

FIGURE 7. Right anterior thoracotomy incision in the (A) right third intercostal space and (B) surgical exposure.

placed through a separate stab incision. Cardioplegia is administered in standard fashion.

Technical details of aortotomy, prosthetic valve implantation, and aortotomy closure are identical to UHS. The aortic valve is excised in usual fashion; however, the right coronary cusp sutures are placed first and retracted to facilitate exposure. Temporary epicardial pacing wires are placed before the aortic crossclamp is removed. Once weaned from bypass, the femoral cannulae are removed. Adequate distal limb perfusion is confirmed. A small chest drainage tube is inserted in the right pleural space through a separate intercostal space. Pericardium is left open.

The disarticulated rib is reattached to the sternum using a figure-of-eight No. 2 nonabsorbable, braided suture. The ribs are reapproximated using 2 separate No. 2 nonabsorbable braided sutures to avoid lung herniation. A long-acting local anesthetic is injected into the intercostals nerve bundle and a reservoir device containing a topical anesthetic is used. The chest incision is closed in routine fashion, and the groin is closed in layers with the aim of compressing lymphatics and eliminating dead space. In obese patients, a drain may help to reduce the risk of hematoma, seroma, and subsequent infection.

Importantly, if exposure with either UHS or RAT is inadequate, then conversion to full sternotomy should be considered. This ensures that valve replacement can be completed safely using an approach familiar to the surgeon. At the end of the converted operation, meticulous attention is devoted to closure of the RAT or UHS to preserve sternal stability.

\section{POSTOPERATIVE}

Postoperative care of patients undergoing MIAVR requires a fundamental change in management philosophy. Simply imposing the clinical pathway for conventional aortic valve replacement to MIAVR fails to leverage advances in best practices. By better preserving integrity of the chest wall, MIAVR is often associated with a faster return to work; 2 to 4 weeks for RAT and 3 to 4 weeks for UHS.

Conduct in the operating room affects postoperative care. To facilitate early extubation, anesthesiologists recognize the importance of moderating the dosages of narcotics, sedatives, and muscle relaxants. Dexmedetomidine, a sedative that causes no respiratory depression, and spinal anesthesia are useful adjuncts. Either complete or near complete rewarming of the patient is achieved while in the operating room. Reservoir devices that allow continuous delivery of topical local anesthetic agents are beneficial. After RAT, incision pain peaks early-within the first 12 to 24 hours; however, with limited rib retraction it subsides rapidly. Residual incisional pain is ameliorated with judicious use of intravenous nonsteroidal antiinflammatory drugs. In general, the use of parenteral narcotics is limited to the first 48 to 72 hours and patientcontrolled analgesic pumps are seldom needed.

In the event of significant bleeding or tamponade, re-exploration should be accomplished through the UHS or RAT incision. Early in the MIAVR experience, a sternal saw and wire cutters should be readily available in the event that emergency re-entry is required.

In general, chest tubes are removed when drainage is $<150 \mathrm{~mL}$ over 8 hours. In most cases, tubes are removed on the first postoperative day. Mobilizing the patient before tube removal helps promote complete drainage from the costophrenic recesses. Temporary pacing wires are removed before drainage tubes if both are being discontinued on the same day. Stable patients are aggressively diuresed, and the threshold to perform thoracentesis or catheter thoracostomy for a residual pleural fluid collection is low.

With MIAVR, many postoperative management considerations mirror conventional AVR. Blood glucose is monitored and hyperglycemia is treated. Physician orders for the indwelling urinary catheter and prophylactic antibiotics automatically sunset. Atrial fibrillation is treated per algorithm. All invasive lines are removed, and the 
patient is ambulated with assistance. Transfer from intensive care to the telemetry unit usually occurs on the first postoperative day. All skin sutures are removed before discharge.

In general, patients are discharged from the hospital between postoperative days 3 and 5. Importantly, this is achieved by anchoring patient expectations preoperatively. All patients are contacted within 72 hours of discharge to assess their overall recovery. Patients are seen by their cardiologist at 2 weeks and by their surgeon between 2 and 4 weeks postdischarge. After RAT, it is especially important to send the operative report to the referring cardiologist and primary care physician, because the absence of a midline incision often leaves little trace of the operation. Standard sternal wound precautions are relaxed, and patients may resume driving once they have ceased taking oral narcotics. Also, physical restrictions on upper extremity range of motion are eased, and heavy lifting is titrated to pain tolerance. If ribs were divided, then 3 weeks of weight restriction is recommended. If not, no physical restrictions apply upon hospital discharge.

\section{DISCUSSION}

Since its first description in 1993, MIAVR has become associated with less bleeding, shorter duration of mechanical ventilation, and reduced intensive care unit and hospital stay despite longer procedure times. Improved cosmesis, less pain and narcotic use, and faster recovery have been reported and generally accepted by MIAVR patients and surgeons.

These benefits are more likely to be verified with standardization of the MIAVR procedure itself, which will greatly facilitate the design and implementation of future clinical studies. This report is intended to provide the basis for a safe, standardized approach to aortic valve replacement via UHS and RAT.

A direct correlation between clinical outcomes and institutional surgical volumes is well established for conventional aortic valve replacement. ${ }^{23}$ Accordingly, surgeons interested in incorporating MIAVR into their armamentarium must have expertise in conventional aortic valve replacement at centers with adequate case volumes; approximately 30 or more aortic valve-related cases per year is suggested.

By first developing fundamental MIAVR skills using the specialized cannulation techniques, neck lines, and longshafted instruments in the setting of conventional full sternotomy, the safest operative environment is afforded the patient. Indeed, the conventional incision can be draped with towels in such a fashion as to simulate the exposure provided by UHS. During this phase, the anesthesiologist and surgeon can refine their technical and communication skills. Only after a sufficient comfort level is achieved by all team members, is UHS even considered. This is a logical next step, because UHS will allow safe conversion to full sternotomy, if necessary. Once UHS is mastered, RAT may be considered. Because RAT is most often performed using peripheral $\mathrm{CPB}$, experience with this cannulation technique can be first obtained as an adjunct to conventional or UHS aortic valve replacement.

\section{References}

1. Rao PN, Kumar AS. Aortic valve replacement through right thoracotomy Texas Heart Inst J. 1993;20:307-8.

2. Cosgrove DL, Sabik JF. Minimally invasive approach for aortic valve operations. Ann Thorac Surg. 1996;62:596-7.

3. Glauber M, Miceli A, Gilmanov D, Ferrarini M, Bevilacqua S, Farneti PA, et al. Right anterior minithoracotomy versus conventional aortic valve replacement: a propensity score matched study. J Thorac Cardiovasc Surg. 2013; 145:1222-6.

4. Brown ML, McKellar SH, Sundt TM, Schaff HV. Ministernotomy versus conventional sternotomy for aortic valve replacement: a systematic review and meta-analysis. J Thorac Cardiovasc Surg. 2009;137:670-9.

5. Brinkman WT, Hoffman W, Dewey TM, Culica D, Prince SL, Herbert MA, et al. Aortic valve replacement surgery: comparison of outcomes in matched sternotomy and port access groups. Ann Thorac Surg. 2010;90:131-5.

6. Tabata M, Umakanthan R, Cohn LH, Bolman RM 3rd, Sheakar PS, Chen FY, et al. Early and late outcomes of 1000 minimally invasive aortic valve operations. Eur J Cardiothorac Surg. 2008;33:537-41.

7. Murtuza B, Pepper JR, Stanbridge DeL R, Jones C, Rao C, Darzi A, et al. Minimal access aortic valve replacement: is it worth it? Ann Thorac Surg. 2008;85:1121-31

8. Raja SG, Navaratnarajah M. Impact of minimal access valve surgery on clinical outcomes: current best available evidence. J Card Surg. 2009;24 73-9.

9. Grossi E, Galloway AC, Ribakove GH, Zakow PK, Derivaux CC, Baumann FG, et al. Impact of minimally invasive valvular heart surgery. Ann Thorac Surg. 2001;71:807-10

10. Johnston DR, Atik FA, Rajeswaran J, Blackstone EH, Nowicki ER, Sabik JR III et al. Outcomes of less invasive J-incision approach to aortic valve surgery. J Thorac Cardiovasc Surg. 2012;144:852-8.

11. Cohn LH, Adams DH, Couper GS, Bichell DP, Rosborough DM, Sears SP, et al Minimally invasive cardiac valve surgery improves patient satisfaction while reducing costs of cardiac valve replacement and repair. Ann Surg. 1997;226: 421-8.

12. Sharony M, Grossi EA, Saunders PC, Schwartz CF, Ribakove GH, Baumann FG, et al. Propensity score analysis of a six-year experience with minimally invasive isolated aortic valve replacement. J Heart Valve Dis. 2004; $13: 887-93$

13. Dogan S, Dzemali O, Wimmer-Greinecker G, Derra P, Doss M, Khan MF, et al Minimally invasive versus conventional aortic valve replacement: a prospective randomized trial. J Heart Valve Dis. 2003;12:76-80.

14. Bonacchi M, Prifti E, Giunti G, Frati G, Sani G. Does ministernotomy improve postoperative outcome in aortic valve operation? A prospective randomized study. Ann Thorac Surg. 2002;73:460-5.

15. Machler HE, Bergmann P, Anelli-Monti M, Dacar D, Rehak P, Knez I, et al Minimally invasive versus conventional aortic valve operations: a prospective study in 120 patients. Ann Thorac Surg. 1999;67:1001-5.

16. Shekar PS. Minimal access aortic valve surgery through an upper hemisternotomy approach. Operat Technique Thorac Cardiovasc Surg. 2010; $15: 321-35$

17. Kurra V, Schoenhagen P, Roselli EE, Kapadia SR, Tuzcu EM, Greenberg R, et al Prevalence of significant peripheral artery disease in patients evaluated for percutaneous aortic valve insertion: preprocedural assessment with multidetector computed tomography. J Thorac Cardiovasc Surg. 2009;137: 1258-64.

18. Jeanmart H, Casselman FP, De Grieck Y, Bakir I, Coddens J, Foubert L, et al Avoiding vascular complications during minimally invasive, totally endoscopic intracardiac surgery. J Thorac Cardiovasc Surg. 2007;133:1066-70.

19. Roselli EE, Pettersson GB, Blackstone EH, Brizzio ME, Houghtaling PL, Hauck R, et al. Adverse events during reoperative cardiac surgery: frequency, characterization, and rescue. J Thorac Cardiovasc Surg. 2008; $135: 316-23$ 
20. Glauber M, Micelli A, Bevilacqua S, Farneti PA. Minimally invasive aortic valve replacement via right anterior minithoracotomy: early outcomes and midterm follow-up. J Thorac Cardiovasc Surg. 2011;142:1577-8.

21. Thys DM, Abel MD, Brooker RF, Cahalan MK, Connis RT, Duke PG, et al. Practice guidelines for perioperative transesophageal echocardiography. An updated report by the American Society of Anesthesiologists and the Society of Cardiovascular Anesthesiologists Task Force ontransesophageal echocardiography. Anesthesiology. 2010;112:1084-96.

22. Byrne JG, Aranki SF, Couper GS, Adams DH, Allred EN, Cohn LH. Reoperative aortic valve replacement: partial upper hemisternotomy versus conventional full sternotomy. J Thorac Cardiovasc Surg. 1999;118:991-7.

23. Dewey TM, Herbert MA, Ryan WH, Brinkman WT, Smith R, Prince SL, et al. Influence of surgeon volume on outcomes with aortic valve replacement. Ann Thorac Surg. 2012;93:1107-13

\section{APPENDIX 1: AUTHOR RECOMMENDED PRODUCTS}

1. Mini sternal retractors

- ValveGate (Geister Medizintechnik GmbH, Tuttlingen, German)

- Window Access SI (Estech, San Ramon, Calif)

2. Aortic cannula

- OptiSite arterial cannula (18, 20, 22 Fr) (Edwards Lifesciences, Irvine, Calif)

- Sarns Soft-Flow (21, 24 Fr) (Terumo Cardiovascular Systems, Ann Arbor, Mich)

3. Triple stage venous cannula

- Thin-Flex (Edwards Lifesciences, Irvine, Calif)

- MC2X (Medtronic, Minneapolis, Minn)

- Three-stage (Terumo Cardiovascular Systems, Ann Arbor, Mich)

4. Multiside hole femoral venous cannula

- QuickDraw (22, 25 Fr) (Edwards Lifesciences, Irvine, Calif)

- Bio-Medicus Multi-Stage (19, 21, 25 Fr) (Medtronic, Minneapolis, Minn)

5. Low-profile aortic clamp

- V. Mueller Cosgrove Flex (CareFusion, San Diego, Calif)

- Cygnet (Vitalitec, Plymouth, Mass)

- ValveGate (Geister Medizintechnik GmbH, Tuttlingen, German)
6. Chest drain

- Blake (Ethicon, Somerville, NJ)

- PleuraFlow (Clear Catheter Systems, Bend, Ore), Active Tube Clearance

7. Sternal plates

- SternaLock Blu (Biomet, Jacksonville, Fla)

- Titanium Sternal Fixation System (DePuy Synthes, West Chester, Pa)

- Sternal Talon (KLS Martin, Jacksonville, Fla)

8. Pain-control pumps

- On-Q PainBuster (I-Flow, Lake Forest, Calif)

- AutoFuser (Moog, Salt Lake City, Utah)

9. Straight-tip angiographic catheters

- Mariner (AngioDynamics, Latham, NY)

- Glidecath (Terumo Cardiovascular Systems, Ann Arbor, Mich)

10. Stiff wire

- Amplatz Extra-Stiff and Ultra-Stiff (Cook Medical, Bloomington, Ind)

- Amplatz Super Stiff (Boston Scientific Corp, Natick, Mass)

11. Femoral arterial cannula

- Fem-Flex II (14, 16, 18, 20 Fr) (Edwards Lifesciences, Irvine, Calif)

- Bio-Medicus (17, 19, 21 Fr) (Medtronic, Minneapolis, Minn)

12. Peripheral retrograde cannula

- ProPlege peripheral retrograde cardioplegia device (Edwards Lifesciences, Irvine, Calif)

13. Peripheral pulmonary artery vent

- EndoVent pulmonary catheter (Edwards Lifesciences, Irvine, Calif)

14. Soft tissue retractor

- Soft tissue retractor (small, medium, large) (Edwards Lifesciences, Irvine, Calif)

- Alexis O (x-small, small, medium) (Applied Medical, Rancho Santa Margarita, Calif) 